\title{
Changes in phagocytic function with glycaemic control in diabetic patients
}

\author{
S M MACRURY, C G GEMMELL, * K R PATERSON, A C MACCUISH \\ From the Diabetic Unit and *Department of Bacteriology, Glasgow Royal Infirmary, Glasgow, Scotland
}

SUMMARY Phagocytic function was assessed by serial whole blood chemiluminescence in poorly controlled type 2 (non-insulin dependent) diabetic patients during efforts to improve glycaemic control and compared with a group of well controlled type 1 (insulin dependent) diabetic patients. Chemiluminescence (corrected to a standard polymorphonuclear count) remained below normal $(0 \cdot 15-0.30$ photons/second/cell) for most of the type 2 patients until 12 weeks when the value was significantly increased in patients showing improved glycaemic control (mean (range) $0.25(0.01-$ $0 \cdot 43)$ photons/second/cell) compared with those showing no improvement $(0 \cdot 12(0 \cdot 01-0 \cdot 31)$ photons/ second/cell). There was a significant inverse correlation of $\triangle \mathrm{HbAl}$ with $\triangle$ chemiluminescence. Although mean chemiluminescence for the type 1 diabetic patients was within the normal range, there was a wide scatter of values $(0 \cdot 19(0.04-0.43)$ photons/second/cell) and there was no significant difference compared with the final value of type 2 patients with improved control.

Glycaemic control is therefore a major determinant of phagocytic function in diabetic patients, but other factors must contribute, particularly in type 1 (insulin dependent) patients.

It is commonly believed that diabetes mellitus increases the susceptibility of patients to infections, especially with yeasts, fungi, staphylococci and Escherichia coli. ${ }^{1}$ This abnormal susceptibility seems to be related to cellular factors ${ }^{2}$ : abnormalities of chemotaxis and adhesion of polymorphonuclear cells (PMN) to endothelial cells have been shown in diabetic patients, ${ }^{3-5}$ but although impaired bactericidal activity has been shown in the PMNs of diabetic patients, ${ }^{6-12}$ assessment of phagocytosis has given conflicting results. Poor glycaemic control has been associated with impaired leucocyte function, ${ }^{13}$ and a few studies have shown an improvement with insulin treatment. ${ }^{3810}$

Chemiluminescence is the measurement of light emission during phagocytosis, the response being due to reactive oxygen species-that is, superoxidewhich is required for antimicrobial activity. This response can be enhanced by the use of zymosan particles. ${ }^{14-16}$ Most studies of white cell function have involved purification of PMN from whole blood and this may well activate the cells thus increasing the extent of chemiluminescence. We therefore measured chemiluminescence of PMNs in whole blood in a

Accepted for publication 12 June 1989 group of poorly controlled type 2 (non-insulin dependent) diabetic patients. Assessment was made at four week intervals for up to 12 weeks during which time efforts were made to improve glycaemic control. In a parallel study we measured chemiluminescence in a group of well controlled type 1 (insulin dependent) diabetic patients for comparison with the final value in the type 2 patients.

\section{Patients and methods}

Group A comprised 19 patients with non-insulin dependent diabetes (10 men, nine women) recruited from the outpatient clinic. The mean age was 54 years (range 34-71 years). One patient was newly diagnosed and managed on diet alone; 18 were known diabetic patients, mean duration of diabetes six years (range six months-20 years); 16 patients had secondary failure on oral hypoglycaemic agents - that is, symptomatic poor glycaemic control on maximum tablet dosage for at least six months following diagnosis of diabetes (nine started a once daily insulin regimen and seven a twice daily regimen). One patient started a sulphonylurea drug after failure to control diabetic symptoms while on a dietary regimen for 18 months and one patient with diabetes of five years duration, with recent compliance problems, resumed dietary 
Table Change in mean (SD) plasma glucose, glycosylated haemoglobin, phagocytic function and PMN cell count from initial 0 value to final value at 12 weeks among patients with and without improvement in glycaemic control

\begin{tabular}{|c|c|c|c|c|}
\hline & \multicolumn{2}{|c|}{$\begin{array}{l}\text { Improvement in glycaemic control } \\
(n=10)\end{array}$} & \multicolumn{2}{|c|}{$\begin{array}{l}\text { No improvement in glycaemic control } \\
(n=9)\end{array}$} \\
\hline & Initial value & Final value & Initial value & Final value \\
\hline $\begin{array}{l}\text { Fasting blood glucose }(\mathrm{mmol} / \mathrm{l}) \\
\text { HbAl }(\%) \\
\text { Chemiluminescence } \\
\text { (photons/second } / \text { cell) } \\
\text { PMN count }\left(\times 10^{9} / 1\right)\end{array}$ & $\begin{array}{l}15.5(3.9) \\
13.9(2.2) \\
0.06(0.02-0.26) \\
3.6(1.0)\end{array}$ & $\begin{array}{l}9.8(3.5) \mathrm{p}<0.001 \\
9.4(1.2) \mathrm{p}<0.001^{*} \\
0.25(0.1-0.43) \mathrm{p}<0.001\end{array}$ & $\begin{array}{l}14.2(3.4) \\
12.8(1.0) \\
0.03(0.01-0.07) \\
3.5(0.7)\end{array}$ & $\begin{array}{l}12.0(2.2) \mathrm{p}<0.01 \dagger \\
12.0(0.9) \mathrm{p}<0.001 \ddagger \\
0.12(0.01-0.31) \\
\mathrm{p}<0.02 \S \\
3.7(0.9)\end{array}$ \\
\hline
\end{tabular}

* Initial $v$ final values

$\$ \S$ Final values, improvement $v$ no improvement in glycaemic control

measures. Group B comprised 10 outpatients with insulin dependent diabetes (eight women, two men), who had been selected for good glycaemic control. Mean age was 26 years (range 20-34 years) and duration of diabetes eight years (range three-16 years). All patients had normal renal function (serum creatinine of $<120 \mu \mathrm{mol} / \mathrm{l}$ ) and were receiving no medication other than treatment for diabetes. There was no clinical evidence of overt infection during the study.

Assessment of phagocytic cell function was performed on venous blood anticoagulated with $\overline{0}$ heparin within one hour of venesection using an automated chemiluminescence detector (Picolite 6500, ? Canberra Packard, Caversham). Serum opsonised $\overrightarrow{.}$ zymosan particles (ZAP, Canberra Packard, $\vec{\overrightarrow{ }}$ Caversham) were used as a stimulus and luminol as a $\vec{\omega}$ scavenger substrate. The reaction mixture (in the dark) 을 comprised whole blood $(20 \mu \mathrm{l})$, ZAP $(200 \mu \mathrm{l})$, and Hanks's balanced salt solution $(200 \mu \mathrm{l})$. The reaction $Z$ was initiated by the addition of ZAP and chemiluminescence was done for 40 minutes at $37^{\circ} \mathrm{C}$.

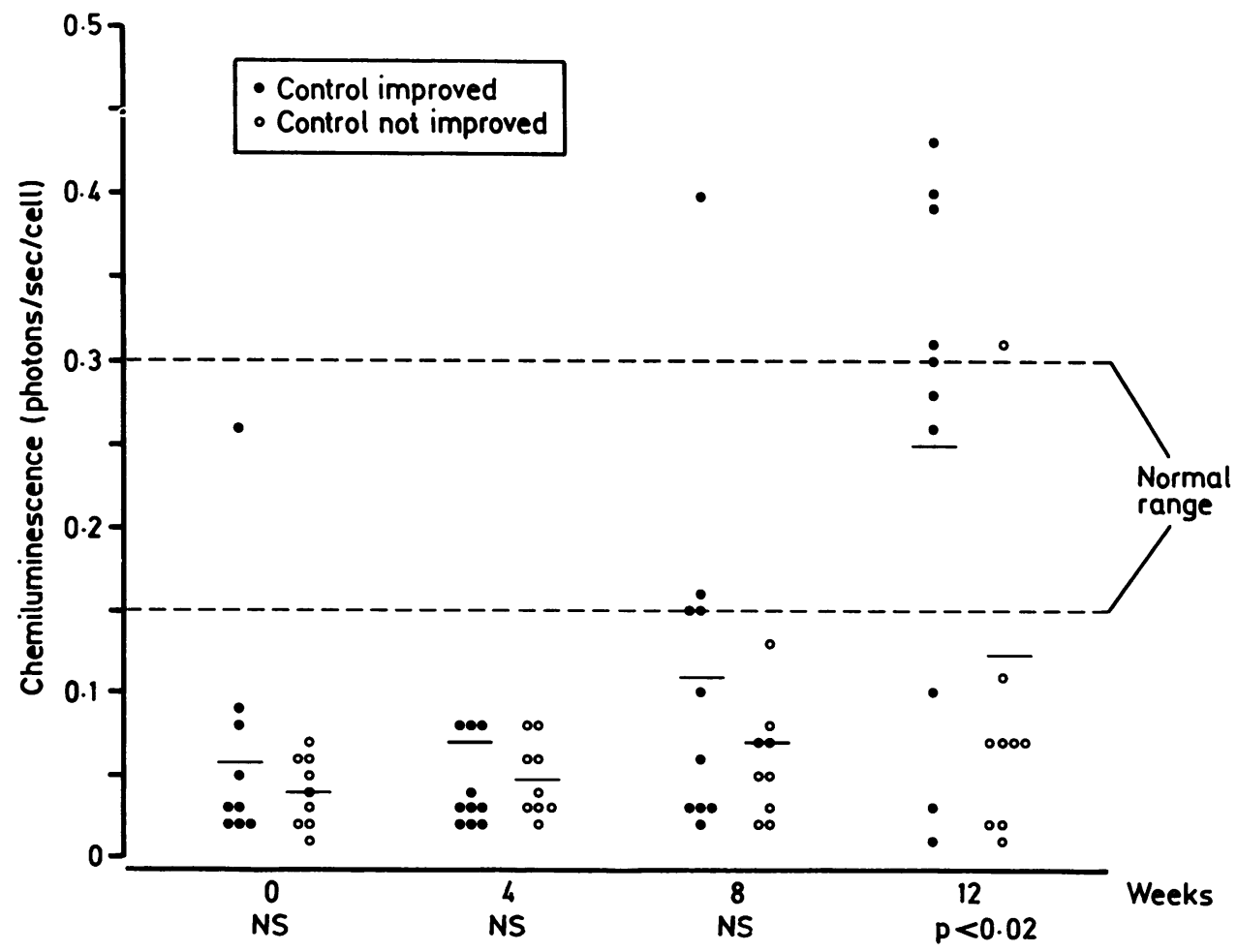

Fig 1 Comparison of serial chemiluminescence at $0,4,8$, and 12 weeks in diabetic patients with improved glycaemic control and those with no change in glycaemic control. 
Phagocytosis was assessed by peak output of light from PMNs (normal range 0.15-0.3 photons/second/ cell). Coefficient of variation of the assay was $0.5 \%$. An increase in chemiluminescence ( $\triangle$ photons/ second/cell) in serial blood samples was taken as an improvement in phagocytic function. Glycosylated haemoglobin (HbAl) was measured by agar gel electrophoresis (Corning Glytrac), our laboratory normal range being $5 \cdot 5-8 \cdot 5 \%$, and white cell count by Coulter S Counter (normal range for PMN count being $\left.2.0-7.5 \times 10^{9} / 1\right)$. Chemiluminescence values were corrected to a standard PMN count of $3.5 \times$ $10^{9} / 1$.

Statistical analysis was by the Wilcoxon rank sum test for paired and unpaired data and Spearman's rank correlation coefficient. Values were expressed as mean $\pm S D$, and chemiluminescence, because the data were skewed, was expressed as median and range unless otherwise stated. Significance levels were taken at $\mathrm{p}<0.05$.

\section{Results}

Mean fasting plasma glucose for group A $(n=19)$ before a change in treatment was 14.9 (3.6) $\mathrm{mmol} / \mathrm{l}$, $\mathrm{HbAl} ; 13.4(1.7) \%$ and chemiluminescence; 0.05 (0.01-0.26) photons/second/cell. Overall, glycaemic control improved in 10 patients over the study period, defined as a fall in $\mathrm{HbAl}$ to within $2 \%$ of upper limit of normal (eight with insulin and two with dietary treatment, $\mathrm{HbA} 1 ; 9.4(1 \cdot 2) \%, \mathrm{p}<0.001)$, but showed no improvement in nine patients (eight with insulin, one with drugs), $12.0(0.9 \%)$, NS) (table). PMN counts remained normal throughout the study (3.6 $(0.9) \times 10^{9} / 1$ initially, to $3.7(1.1) \times 10^{9} / 1$ for all patients in group $\mathbf{A})$.

Only one patient in group $\mathrm{A}$ had normal phagocytic function initially, defined by a chemiluminescence value within the normal range $(0.26$ photons/second/ cell). Phagocytic function, however, improved in seven out of 10 patients showing improvement in glycaemic control and failed to improve in eight out of nine patients showing no change in control-that is, chemiluminescence values remained below the normal range in the latter group in all but one patient ( $p<0.01$, Fisher's exact probability test). Serial values of chemiluminescence increased significantly between 8 and 12 weeks in the group showing improvement in phagocytosis $(0.11(0.02-0.40) v 0.25$ $(0.01-0.43), p<0.02)$ (fig 1$)$, and at 12 weeks in this group the value was significantly higher than the final value for the group with no improvement in phagocytosis $(0.25(0.01-0.43) v 0.12(0.01-0.31)$ photons/ second/cell, $p<0.02$ ). Typical serial values of HbAl and chemiluminescence for two sample patients are shown in fig 2.

Mean $\mathrm{HbAl}$ in group $\mathrm{B}$ insulin dependent diabetes
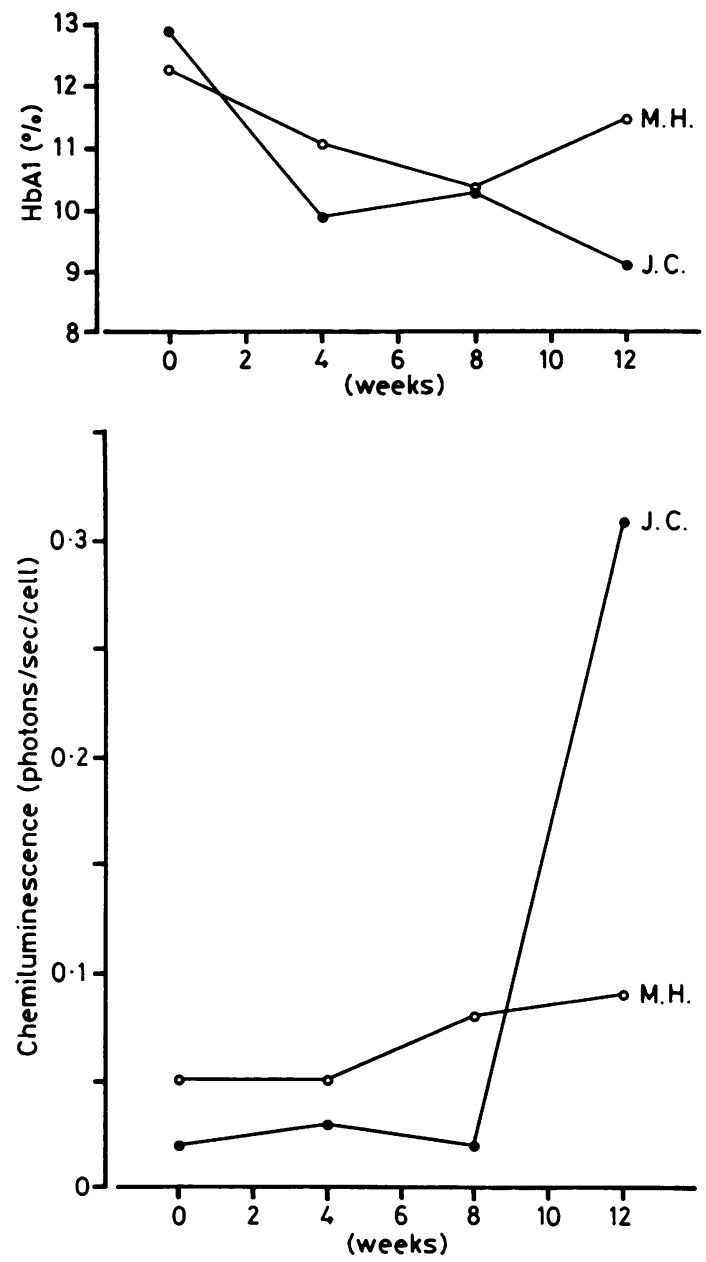

Fig 2 Serial $\mathrm{HbAl}$ and chemiluminescence for a sample patient whose glycaemic control failed to improve (M.H.) and a patient with improved glycaemic control (J.C.).

mellitus was within the non-diabetic range $(8 \cdot 3$ $(0.9) \%)$ and chemiluminescence 0.19 (0.04-0.43) photons/second/cell (fig 3) was not significantly different from the final value of the type 2 patients with improved glycaemic control. PMN count was $5 \cdot 2(1 \cdot 2)$ $\times 10^{9} / 1$.

There was a significant correlation of change in chemiluminescence with change in $\mathrm{HbAl}(\mathrm{r}=-0.39$, $p<0.05)$ in the non-insulin dependent diabetes mellitus group. No significant correlations of chemiluminescence with fasting glucose, $\mathrm{HbAl}$, or PMN counts were found in the study population.

\section{Discussion}

Phagocytosis depends on the ability of the white cell to 


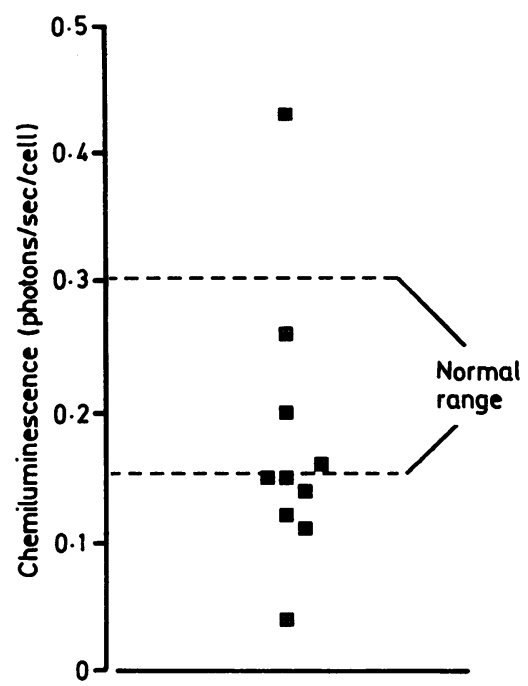

Fig 3 Chemiluminescence in type 1 insulin dependent patients.

deform and adapt to engulf particulate material for intracellular killing. It is possible to measure phagocytosis in PMNs by incubation techniquesthat is, estimating the percentage of bacteria left extracellularly after a set period of time. Using such methods, Bybee and Rogers first showed that phagocytosis was similar in PMNs from diabetic and nondiabetic subjects unless ketoacidosis was present, this being associated with reduced phagocytic function. ${ }^{17}$ Since then there has been a study of phagocytic cell function in diabetic children which found no difference when a comparison was made with nondiabetic control subjects, ${ }^{9}$ and a similar study of type 1 adult diabetic patients also found no difference when compared with healthy controls. ${ }^{12}$

From our findings and those of others, it seems likely that glycaemic control can affect the ability of the white cell to phagocytose bacteria..$^{13}$ Exposing normal PMNs to increasing concentrations of glucose has produced conflicting results, with some studies showing reduced phagocytosis ${ }^{1218}$ and others showing no change. ${ }^{1920}$ Several incubation studies, mainly cross-sectional, in diabetic patients have related impaired phagocytic function to poor glycaemic control. ${ }^{610}$ In one longitudinal study an increase in phagocytosis was found after two to three weeks of improved control, ${ }^{8}$ and using an artificial pancreas seems to improve phagocytic function. ${ }^{10}$ Using similar methods other studies have found reduced phagocytosis in diabetic patients but have failed to find an association with metabolic control. ${ }^{718}$

Intracellular killing of organisms is mediated by a variety of antimicrobial agents-for example, free ${ }_{0}$

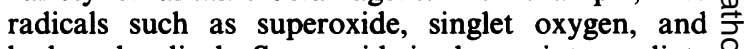

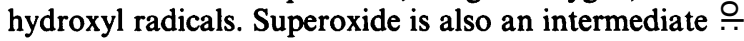
in the formation of hydrogen peroxide, which, along $\vec{\Rightarrow}$ with myeloperoxidase and a halide, forms a powerful $\stackrel{?}{?}$ antimicrobial system. The oxidase enzyme that is responsible for superoxide generation is found in the $\frac{\bar{D}}{\bar{D}}$ cell membrane and oxidative metabolism is stimulated $\frac{\mathscr{D}}{\vec{D}}$

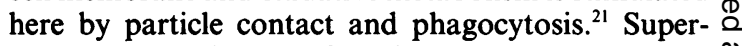
oxide is a substrate for the enzyme superoxide कै dismutase and this enzyme will also increase as $\overrightarrow{0}$ superoxide concentrations increase.

Chemiluminescence therefore reflects the res- $\vec{\omega}$ piratory burst of energy following particle contact at the cell surface. Shah et al found that in the resting ? state there was no difference in chemiluminescence $\mathrm{N}$ between PMNs from diabetic and non-diabetic patients, but when stimulated with zymosan the $\overrightarrow{\overrightarrow{.}}$ response was reduced in the diabetic patients. ${ }^{22}$ Wilson $\overrightarrow{\vec{A}}$ et al, using Candida cells as a stimulus and $\vec{\omega}$ chemiluminescence as a measure of intracellular kill- 음 ing, found that killing was impaired by high glucose concentrations. They postulated that excess glucose $z$ was being metabolised via the polyol pathway to sorbitol with NADPH used as an energy source, thus 3 depriving the membrane oxidase of energy and reducing superoxide production."

Using zymosan and chemiluminescence enhance $\stackrel{8}{\circ}$ by luminol, we have confirmed that phagocytosis in polymorphonuclear cells from whole blood is reduce in diabetic patients compared with control values. Although we found no correlation with blood glucose or $\mathrm{HbAl}$ concentrations, this seems to be related to glycaemic control as values returned to normal range $\stackrel{\square}{\unrhd}$ in those patients whose metabolic control improved $\overrightarrow{\vec{F}}$ during the 12 weeks studied. Interestingly, in the $\frac{3}{3}$ patients with type 1 diabetes, although they all had HBA1 concentrations within the non-diabetic range and the mean chemiluminescence value was within the normal range, most of the individual values were at the ? lower limit of normal with some being below normal. This would suggest that some other factor may affect phagocytic function in insulin dependent patients. In a recent study Tater $e t$ al found that although there was no difference in phagocytosis between type 1 diabetic 9 patients and non-diabetic controls, phagocytosis was $\rightarrow$ reduced in the non-diabetic cells when incubated with diabetic sera. They also found a reduced number of $\mathrm{Fc} \overrightarrow{\mathrm{N}}$ receptors on the PMNs in the diabetic group. ${ }^{12}$

In summary, using whole blood to prevent activa- N tion of polymorphonuclear cells, we have found $\stackrel{\mathrm{W}}{\mathrm{N}}$ reduced phagocytosis in poorly controlled diabetic $\widetilde{O}$ patients. In a longitudinal study we have shown that 0 this can be corrected with improved glycaemic control in type 2 patients, and although phagocytic function is $\stackrel{\mathcal{D}}{+}$ related to glycaemic control in type 1 diabetic patients, $T$ 
other factors may be involved. The exact mechanisms affecting phagocytic function remain unclear but are probably related to changes in the white cell membrane, and further studies to examine receptors for binding organisms and microviscosity of the membrane would be of interest. Nevertheless, it remains important to maintain good glycaemic control in all diabetic patients to reduce the incidence of infection.

We thank F McMillan and E Sloan for technical assistance and $\mathbf{P}$ Harris for illustrations.

\section{References}

1 Wheat LJ. Infection and diabetes mellitus. Diabetes Care 1980;3:187-97.

2 Robertson HD, Polk HC. The mechanism of infection in patients with diabetes mellitus: A review of leucocyte malfunction. Surgery 1974;75:123-8.

3 Mowat AG, Baum J. Chemotaxis of polymorphonuclear leucocytes from patients with diabetes mellitus. $N$ Engl $J$ Med 1971;284:621-81.

4 Andersen B, Goldsmith GH, Spagnuolo PJ. Neutophil adhesive dysfunction in diabetes mellitus: the role of cellular and plasma factors. J Lab Clin Med 1988;111:275-85.

5 Bagdade JD, Stewart M, Walters E. Impaired granulocyte adherance: a reversible defect in host defense in patients with poorly controlled diabetes. Diabetes 1978;27:677-81.

6 Bagdade JD, Root RK, Bulger RJ. Impaired leucocyte function in patients with poorly controlled diabetes. Diabetes 1974;23:9-15.

7 Tan JS, Andersen JL, Watanakinakorn C, Phair JP. Neutrophil dysfunction in diabetes mellitus. J Lab Clin Med 1975;85:26-33.

8 Nolan CM, Beaty HN, Bagdade JD. Further characterisation of the impaired bactericidal function of granulocytes in patients with poorly controlled diabetes. Diabetes $1982 ; 27: 889-94$.

9 Dziatkowiak H, Kowalska M, Denys A. Phagocytic and bactericidal activity of granulocytes in diabetic children. Diabetes 1982;31:1041-3.

$10 \mathrm{Gin} \mathrm{H}$, Brottier E, Aubertin J. Influence of glycaemic normalisa- tion by an artificial pancreas on phagocytic and bactericidal functions of granulocytes in insulin-dependent diabetic patients. J Clin Pathol 1984;37:1029-31.

11 Wilson RM, Tomlinson DR, Reeves WG. Sorbitol production in diabetic neutrophils impairs oxidative killing. Diabetic Medicine 1987;4:37-40.

12 Tater D, Tepaut B, Bercovici JP, Youinou P. Polymorphonuclear cell derangements in type 1 diabetes. Horm Metabol Res 1987;19:642-7.

13 Rayfield EJ, Ault MJ, Keusch GT, Brothers MJ, Nechemias C, Smith $\mathrm{H}$. Infection and diabetes: The case for glucose control. Am J Med 1982;72:439-50.

14 Stjernholm RL, Allen RC, Steele RH, Waring WW, Harris JA. Impaired chemiluminescence during phagocytosis of opsonised bacteria. Infect Immun 1973;7:313-4.

15 Rosen H, Klebanoff SJ. Chemiluminescence and superoxide production by myeloperoxidase-deficient leucocytes. $J$ Clin Invest 1976;58:50-60.

16 Babior JD, Kipnes RS, Curnutte JT. The production by leucocytes of superoxide, a potential bactericidal agent. $J$ Clin Invest 1973;52:741-4.

17 Bybee JD, Rogers DE. The phagocytic activity of polymorphonuclear leucocytes obtained from patients with diabetes mellitus. J Lab Clin Med 1964;64:1-13.

18 Davidson NJ, Sowden JM, Fletcher J. Defective phagocytosis in insulin controlled diabetes: Evidence for a reaction between glucose and opsonising proteins. J Clin Pathol 1984;37:783-6.

19 Pickering LK, Cleary TG, Getz S. Effect of glucose concentration and time on polymorphonuclear leucocyte function. J Clin Lab Immunol 1982;8:31-5.

20 Wilson RM, Reeves WG. Neutrophil phagocytosis and killing in insulin-dependent diabetes. Clin Exp Immunol 1986;63:478-84.

21 Goldstein IM, Cerqueira M, Lind SS, Kaplan HB. Evidence that the superoxide-generating system of human leucocytes is associated with the cell surface. J Clin Invest 1977;59:249-54.

22 Shah SV, Wallin JD, Eilen SD. Chemiluminescence and superoxide anion production jy leucocytes from diabetic patients. $J$ Clin Endocrinol Metab 1983;57:402-9.

Requests for reprints to: Dr S M MacRury, Diabetic Unit, Wards 4 and 5, Glasgow Royal Infirmary, Castle Street, Glasgow G4 OSF, Scotland. 